\title{
An unfinished quest
}

\section{Quirks of the AIDS virus, as much as human bungling, are stalling progress.}

\section{Shots in the Dark: The Wayward Search for an AIDS Vaccine \\ by Jon Cohen}

W. W. Norton: 2001. 440 pp. $\$ 27.95$

\section{Dennis R. Burton}

With 22 million dead from AIDS and the threat of countless millions more to follow (current infection rates are estimated at 100,000 people per week), the search for a vaccine against the human immunodeficiency virus (HIV) is one of the most urgent and important priorities facing biomedicine. This quest has been followed by the science writer Jon Cohen since its beginnings in the early 1980s, and is now documented in Shots in the Dark. The title and its subheading - "The wayward search for an AIDS vaccine" - give notice that this is a critical account. Jon Cohen has been reporting on AIDS for the journal Science for some ten years and is very highly regarded by researchers in the field.

His book is a long one, totalling more than 400 pages, and is woven from two main strands. The first is a detailed account of the principal events and characters of AIDSvaccine science and politics, from the first brash announcement in 1984 that there would be a vaccine within three years, to the present day. The second strand is the author's own search for why we still lack a vaccine, where he considers we have gone wrong, and how we could do better. The historical account is fascinating, very well researched and sourced, and should be required reading for anyone wishing to understand the efforts to develop an AIDS vaccine. From White House press secretary Larry Speakes' joking about gay cruising and AIDS in 1982, through to the present controversy about testing subunit vaccines in the United States and Thailand, Cohen presents an authoritative, highly readable and objective narrative.

The author's search within a search is provocative, but in my opinion somewhat less persuasive. Let me not overreach here. Cohen struggles constantly to deal fairly with difficult issues and never resorts to cheap shots or preaching. He focuses on two themes. One is the suggestion that AIDS-vaccine research has lacked central direction (for which the National Institutes of Health (NIH) is criticized). Cohen calls for a 'Manhattan' project, analogous to the concentrated effort of scientists from many subdisciplines to develop the atomic bomb. The second theme is the struggle between 'empiricists', who favour early and many clinical trials, and 'reductionists', who desire more information before committing to large-scale trials.

The call for a Manhattan project has some

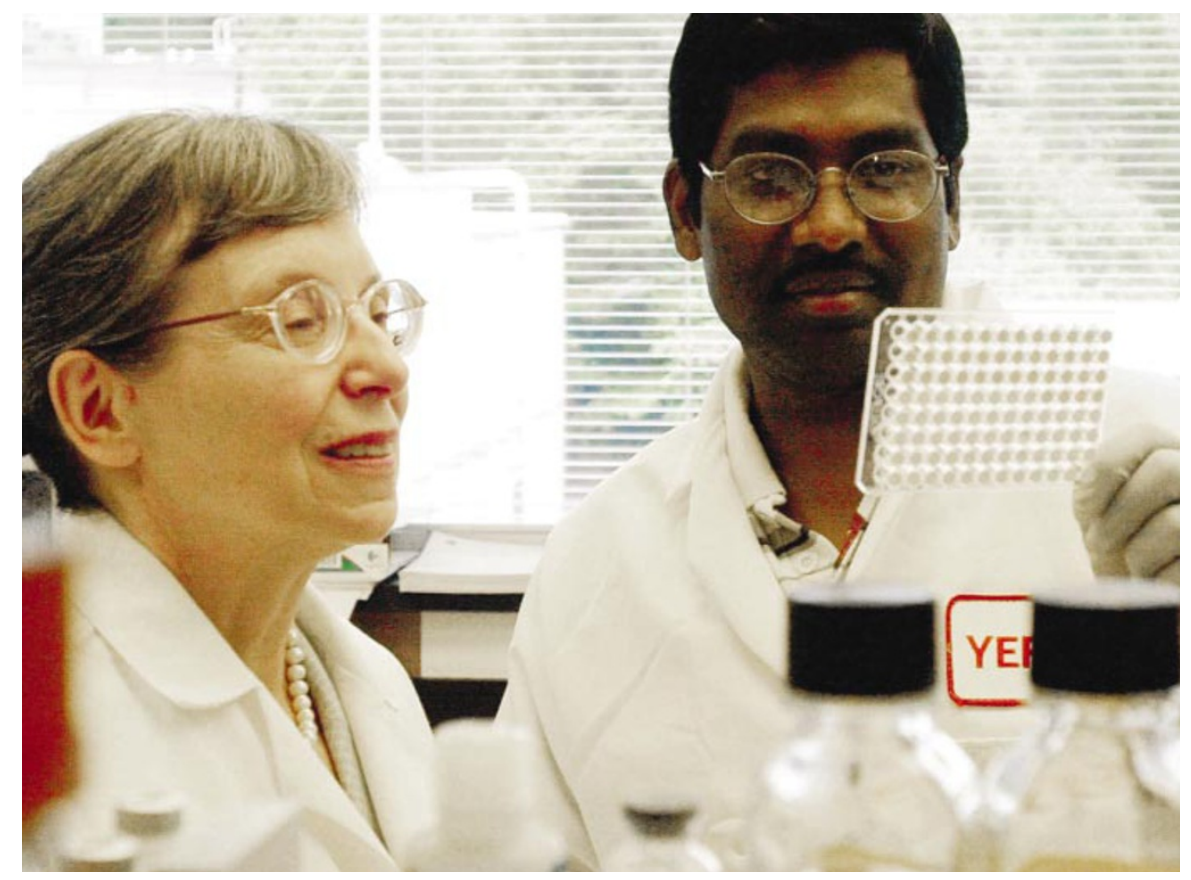

The virus's formidable arsenal of evasive strategies is a major challenge for AIDS-vaccine workers, seen here examining a plate used to measure immune cells.

merit and there have been increasing moves in that direction, particularly from the International AIDS Vaccine Initiative. One needs, however, to temper all criticisms of the NIH, given that this organization is one of the great success stories of the twentieth century. AIDS research in all areas has been built on the rock of NIH funding, and most HIV vaccine research has been, and will continue to be, funded by the NIH. Certainly, the organization suffers from the inflexibility inherent in a large federal bureaucracy and mistakes have been made, but it is not responsible for a 'wayward search' for an AIDS vaccine. The author sometimes sees the problems of AIDS-vaccine development too much in terms of human bungling and not enough in terms of the quirky properties of the virus itself, which has evolved a formidable arsenal of strategies for avoiding immune responses - thereby presenting major problems for vaccine developers.

The empiricism versus reductionism argument is a complex one, sometimes unhelpfully simplified by key protagonists in the book. The late Jonas Salk, for instance, lamented scientists who "mainly seek answers to the most basic questions dissecting the squirrel to see why it climbs the tree - and there is no detectable push to translate those data into experimental vaccines". This notion of scientists in ivory towers is more and more a myth. If altruism does not provide the necessary push, then surely, in the modern age of biotechnology, the profit motive will.

Others accuse the NIH culture of undervaluing applied research, but then many scientists would argue that there must be something worthwhile to apply. In AIDSvaccine research, until recently, there have been very few data of sufficient promise to support a vaccine efficacy trial. In 1995, a meeting was organized at which the assembled scientists "all understood that Thailand urgently needed to try something - even something that had only an outside chance of working". Is it wise to spend millions of dollars on clinical trials that have only an outside chance of working?

To return to empiricism versus reductionism, all science has a strong empirical component. Every experiment is something of a shot in the dark: if we knew what the result of an experiment was going to be, we wouldn't need to do it. Nevertheless, we constantly make judgements about the worth of following a particular path or taking a particular shot in the dark. Not all shots can or should be taken. It would seem that Cohen joins the contingent who believe that judgement in the HIV-vaccine field has been made too often in favour of restraint. Some of us disagree - arguing that at least the gun should be loaded with live ammunition before shooting in the dark — but doubtless the controversies will continue.

As a scientist, I had a number of other 
different perspectives from the author. Sometimes I wanted to plead with him that it is not only the guy frenetically running around organizing, planning and talking about vaccine programmes, but also the bench scientist working to solve some crucial problem, who is making big contributions. I was irritated at times by his tendency, Hollywood-style, to embrace mavericks, some of whose work has not stood the test of time. I was also puzzled by the omission of any reference to the solution of the structure of the virus surface protein gp120, which I believe will eventually be seen as a major milestone on the route to an HIV vaccine. But, reservations aside, my emphatic overall conclusion is that this is an excellent book which demands to be read.

Dennis R. Burton is in the Department of Immunology, Scripps Research Institute, 10550 North Torrey Pines Road, La Jolla, California 92037, USA.

,

\section{Fungal}

\section{fables}

Slayers, Saviors, Servants, and Sex: An Exposé of Kingdom Fungi by David Moore

Springer: 2001. 175 pp. \$29.95, $£ 20$

\section{Nicholas J. Talbot}

Collecting wild mushrooms is not generally viewed as a pastime for the truly adventurous. But there is a group of thrill-seeking mushroom collectors who attempt to distinguish between two almost identical species: one, Amanita caesarea, is perfectly edible, whereas the other, the death cap mushroom Amanita phalloides, will invariably kill you. Indeed, eating just one cubic centimetre of the death cap is thought sufficient to kill the average person. This story of the lunatic fringe of mycologists (presumably a rapidly dwindling group) is one of the anecdotes recounted in David Moore's new celebration of the fungi. The author is a big fan of moulds in all their various forms, and conveys his enthusiasm consistently throughout this quirky but entertaining book.

Fungi are important. This is the central message of Moore's book and one that he illustrates with numerous examples. Fungal diseases kill humans, kill crops and rot harvested foods. In describing the spectacular epidemics and diseases caused by fungi the book is compelling. The symptoms of St Anthony's fire, for example, are given in grisly detail: burning fevers, hallucinations, swollen limbs, severe inflammation followed by numbing of the extremities and complete loss of fingers, toes, arms and legs. All are caused by the ergot fungus Claviceps purpurea, consumed in contaminated rye

\section{The injured and the ingenious}

A case of brittleheart has decimated the sycamore tree (Platanus occidentalis) shown on the right. Its trunk has been hollowed out by the action of fungi, putting it at risk of collapsing with the next bout of windy weather. The strange-looking tree shown below is the aptly named sackof-potatoes or Socotran desert rose tree (Adenium obesum sokotranum), which is found on the Indian Ocean island of Socotra. Its swollen trunk stores essential water. Trees by Roland Ennos (Natural History Museum, London, $£ 9.95$, \$14.95) explores the world of this most familiar group of living organisms.

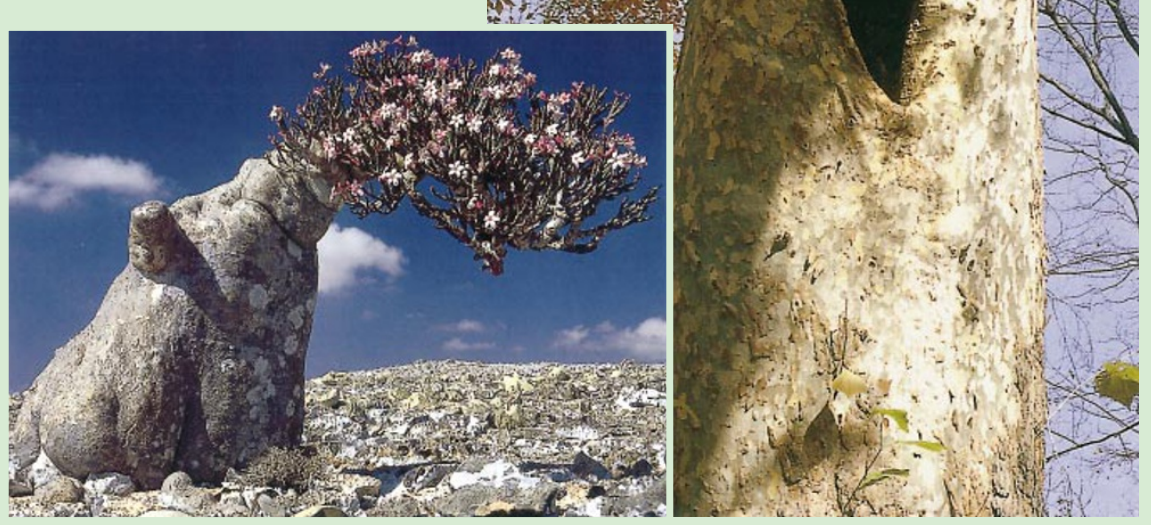

bread. One outbreak of the disease reputedly killed 40,000 people in France in AD 944, and ergotism has even been suggested to have been the cause of symptoms that took hold of eight young girls in Salem and led to the witch trials of 1692. This story, and the production of potent toxins such as $\alpha$-amanitin and aflatoxin, are used to demonstrate that fungi demand our respect.

The beneficial applications of fungi, from gastronomy to bioremediation, are given equal coverage. Fungi are, of course, well known as producers of antibiotics, and the story of the discovery of penicillin has been told many times. But our modern dependence on antibiotics is poignantly illustrated here by the story of Albert Alexander, a British policeman who died in 1941 after being scratched by a rose thorn. Initial treatment with the newly available penicillin made him well enough to sit up in bed, but he quickly succumbed to his infected wound once supplies of the drug ran out. The discovery and application of the immunosuppressant cyclosporin, and the best-selling cholesterol-lowering agents, the statins - both natural fungal products — are similarly well described.

Although relatively light-hearted and anecdotal in style, there is a serious underlying theme throughout the book, because David Moore is clearly not a happy man. He is unhappy that fungi are viewed only as curiosities and consequently occupy, in his view, the peripheries of mainstream science. Ignored by biology departments pensioning off mycologists, by funding agencies, simplistic politicians and international development bodies, fungi offer tremendous untapped potential but are constantly overlooked. Having devoted a career to their study, Moore wants us to know he is annoyed. He also describes the history of mycology as littered with the 'nearly' men of science: the Reverend Miles J. Berkeley, who studied the origin of the potato-blight epidemic and anticipated the germ theory of Louis Pasteur by almost 25 years, but did not prove his case; and Agostino Bassi who, similarly, recognized fungi as agents of disease at an even earlier date.

It is here that I take issue with Moore's thesis. As this year's Nobel prize for medicine aptly demonstrated, fungi are at the centre of scientific endeavour. From the onegene-one-enzyme theory to the control of cell division, we have learned a huge amount of fundamental biology from fungi. Indeed, this is the most striking omission in the book, because if there is one thing about fungi of which the public are really uninformed, it is their use in biomedical research. Fungi, both yeasts and filamentous species, are superlative experimental 